\title{
Displaying of Digital Clock through digital circuits and through Assembly Language Programs of 8051 microcontroller
}

\author{
Dr. D. Chinni Krishna ${ }^{*}$ and U. Sridevi** \\ *Department of Physics, Bhavan's New Science College, Narayanaguda, Hyderabad-500 029, Telangana State, \\ India. \\ **Department of Mathematics, Govt. City College, Nayapul, Hyderabad-500 001, Telangana State, India
}

\begin{abstract}
With a view to display a Digital Clock through digital circuits using modulo-n (mod-n) counters, a circuit diagram was designed and implemented it through multi simulation software. In the similar manner the time digits were displayed on seven segment displays at 8255 programmable peripheral interface (PPI) ports through 8051 microcontroller, the time digits (hours, minutes and seconds) were connected to the first 8255 PPI and the date digits (Years, months and days) were connected to second 8255 PPI. The detailed circuit diagram was given to understand the construction details of the circuit. The loop in a loop technique of assembly language program was used to display date and time. After displaying a year, month and day on the date displays through main program, it calls 1day subroutine to display time in 24 hours clock. The 1day subroutine calls 1second delay subroutine to change the digits in seconds display. After completion of 24 hours time, the digit will be changed in the days display to indicate the next date. After completion of 31 days in the first month, the main program calls month subroutine to change the digit in the months display. Precautions were taken to change the digits in months display for January 31 days, February 28 days, March 31 days, April 30 days, May 31 days, June 30 days, July 31 days, August 31 days, September 30 days, October 31 days, November 30 days and December 31 days. After completion of a month, there will be a change in years digit and this process will be repeated continuously.

Keywords: Digital Clock, Modulo-n Counters, Interfacing, Assembly Language program, Loop in Loop technique, Binary Coded Decimal (BCD) number
\end{abstract}

\section{INTRODUCTION}

In the digital era, designing of a digital clock and maintaining of its digits without any error is one of the important tasks of the circuit designer. The sequential circuits of digital electronics were implemented to design the clock. The modulo-n counters are used to give the required data to display the digits of a digital clock on 7 segment displays.

\section{RESULTS AND DISCUSSIONS}

The general circuit diagram of 24 hours Digital Clock with digital circuits as given in a text book [1] with clock input was designed by using mod-n counters as shown in Fig. 1.

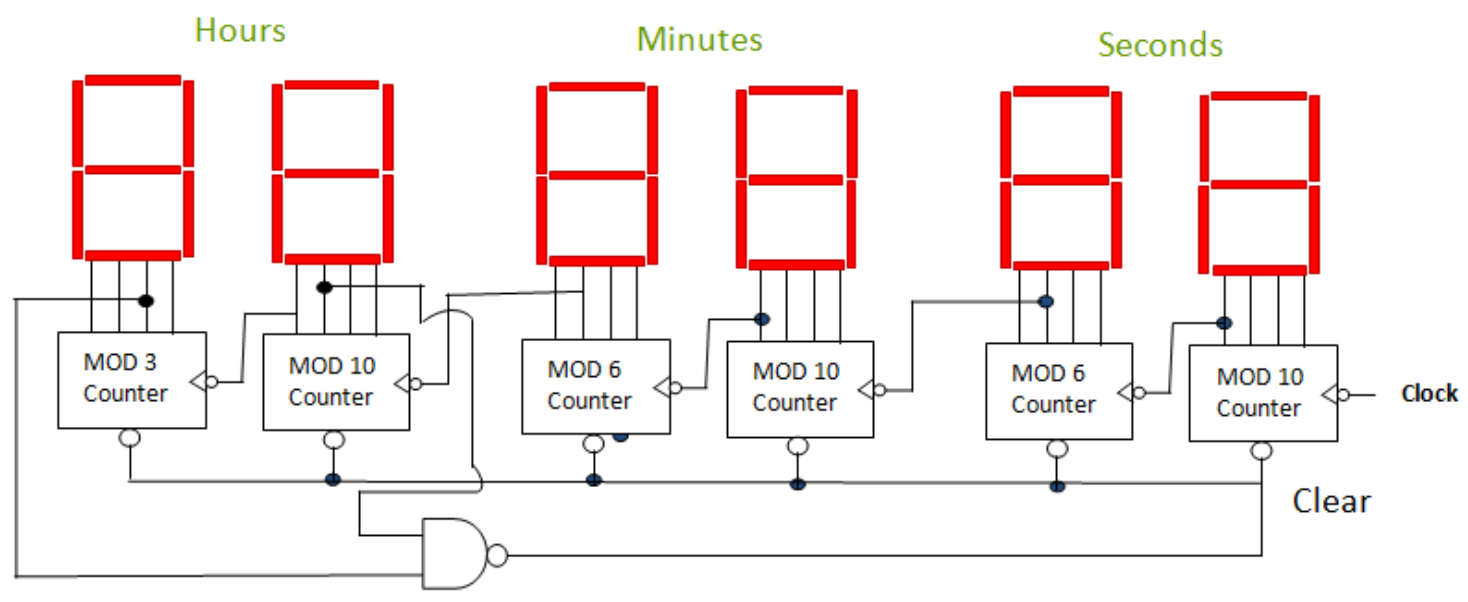

Fig. 1. Digital clock by using mod-n counter digital circuits 
The practical circuit diagram to design a 24 hours digital clock by using mod-n counters on Multi- simulation software [2] with execution results were shown in Fig. 2.

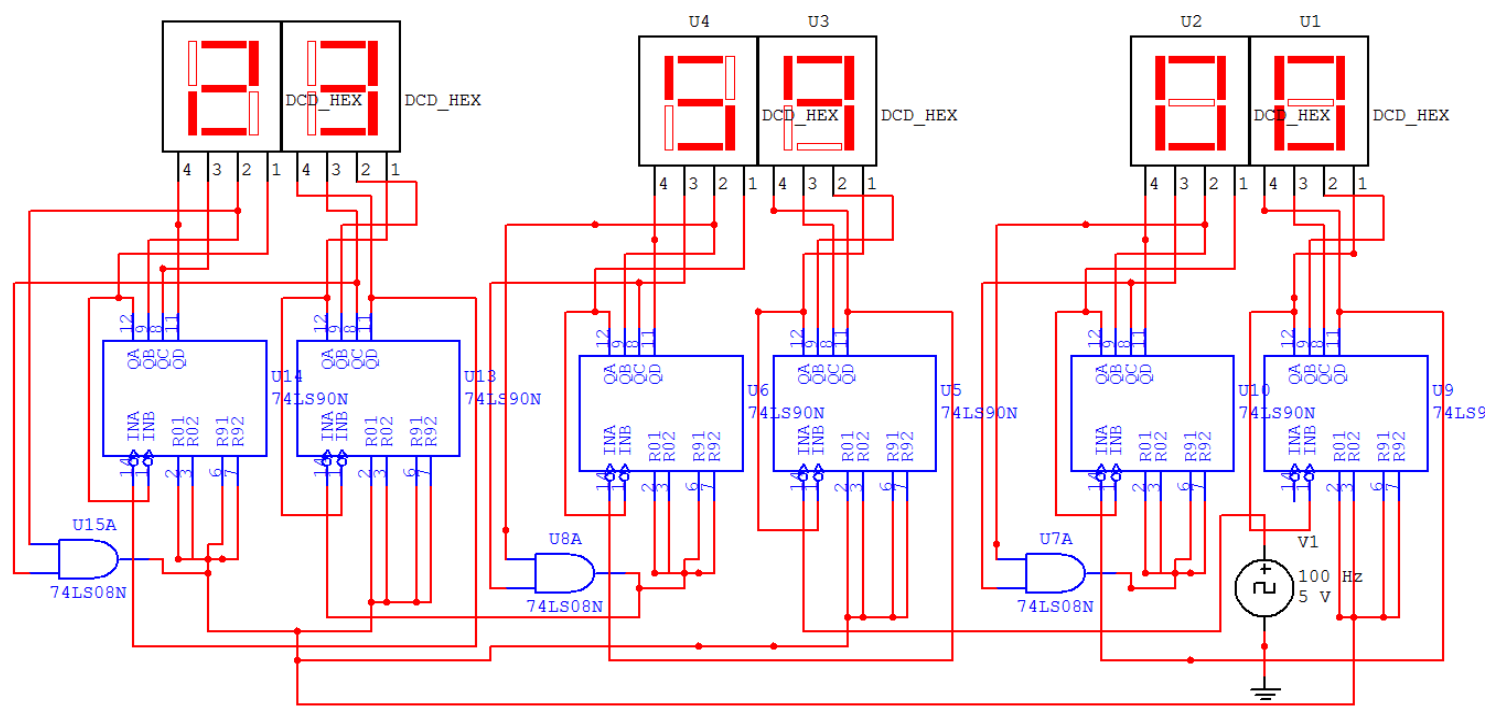

Fig. 2. The 24 hours digital clock

It is observed from figure 2 that, each digit in LSB reaches its required value may apply a clock pulse to its next higher digit. When the clock pulse reached to minutes place, it clears all digits in seconds place. Similarly, when a clock pulse reached to hours place, then all digits in minutes and seconds place will be cleared. When it reaches highest value all digits were cleared and it repeated in incrementing mode. Change the clock position to set or reset any of the digits in a digital clock.
The experimental diagram to display Time and date through 8051 microcontroller as its ports information given in a text book [3] was given in Fig. 3. One 8255 ports are used to control the Time digits and another 8255 PPI ports are used to control the digits of the date. The Table 1 shows the 8255 ports bit conditions to display time and date in a systematic manner.

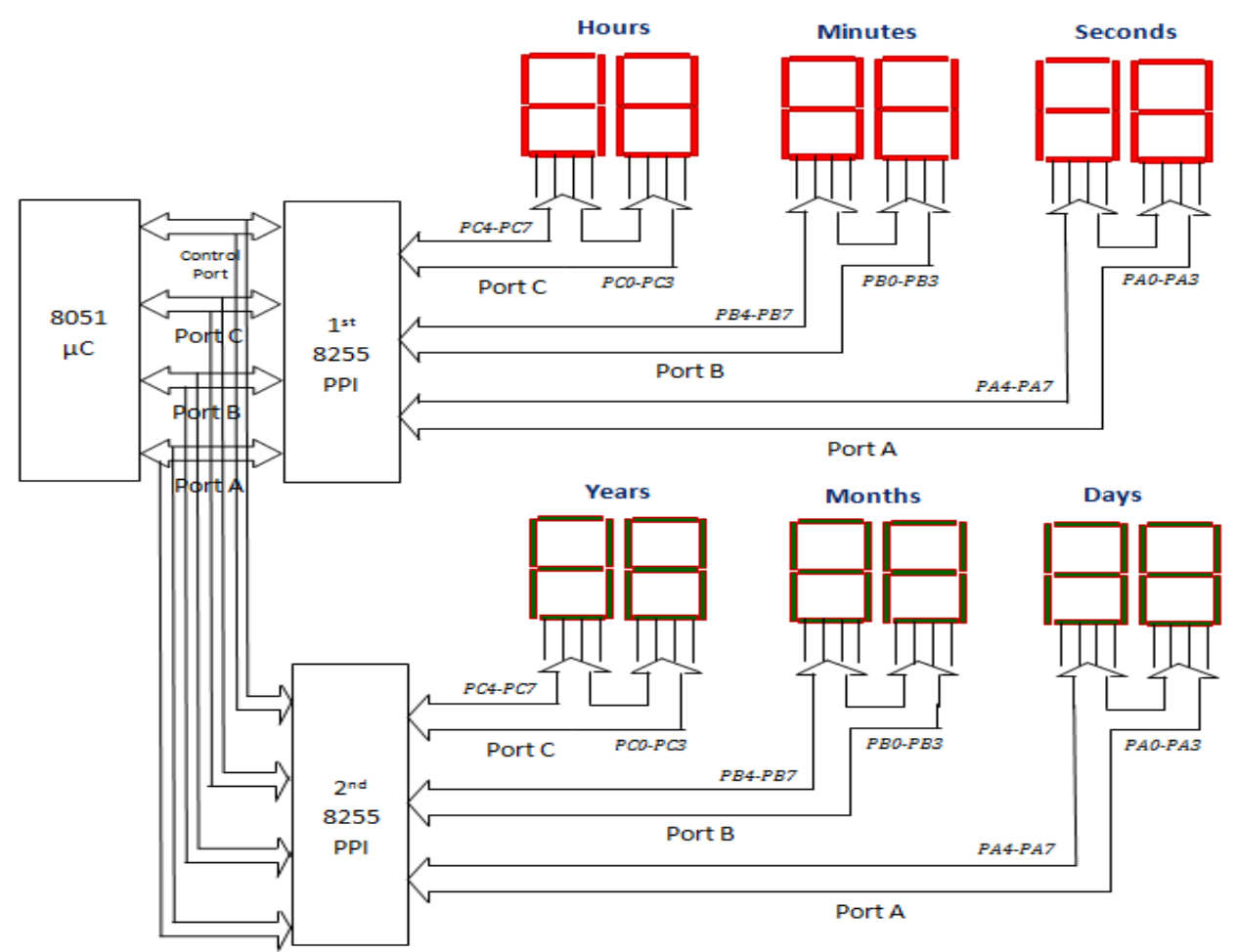

Fig. 3. Displaying of Time and Date through 8051 microcontroller and 8255 PPI ports 
Displaying of Digital Clock through digital circuits and through Assembly Language Programs of ..

Table 1. Pattern of displaying time and days on seven segment displays

\begin{tabular}{|c|c|c|c|c|c|c|c|c|c|c|c|}
\hline \multicolumn{2}{|c|}{ Years } & \multicolumn{2}{|c|}{ Months } & \multicolumn{2}{|c|}{ Days } & \multicolumn{2}{|c|}{ Hours } & \multicolumn{2}{|c|}{ Minutes } & \multicolumn{2}{|c|}{ Seconds } \\
\hline $\begin{array}{l}\text { Upper } \\
\text { Digit }\end{array}$ & $\begin{array}{c}\text { Lower } \\
\text { Digit }\end{array}$ & $\begin{array}{l}\text { Upper } \\
\text { Digit }\end{array}$ & $\begin{array}{c}\text { Lower } \\
\text { Digit }\end{array}$ & $\begin{array}{l}\text { Upper } \\
\text { Digit }\end{array}$ & $\begin{array}{c}\text { Lower } \\
\text { Digit }\end{array}$ & $\begin{array}{l}\text { Upper } \\
\text { Digit }\end{array}$ & $\begin{array}{l}\text { Lower } \\
\text { Digit }\end{array}$ & $\begin{array}{l}\text { Upper } \\
\text { Digit }\end{array}$ & $\begin{array}{c}\text { Lower } \\
\text { Digit }\end{array}$ & $\begin{array}{l}\text { Upper } \\
\text { Digit }\end{array}$ & $\begin{array}{l}\text { Lower } \\
\text { Digit }\end{array}$ \\
\hline 1 & 6 & 0 & 1 & 0 & 0 & 0 & 0 & 0 & 0 & 0 & 0 \\
\hline 1 & 6 & 0 & 1 & 0 & 0 & 0 & 0 & 0 & 0 & 0 & 1 \\
\hline 1 & 6 & 0 & 1 & 0 & 0 & 0 & 0 & 0 & 0 & 0 & 2 \\
\hline 1 & 6 & 0 & 1 & 0 & 0 & “" & "“ & “" & “" & "“ & “" \\
\hline 1 & 6 & 0 & 1 & 0 & 0 & 0 & 0 & 0 & 0 & 0 & 9 \\
\hline 1 & 6 & 0 & 1 & 0 & 0 & 0 & 0 & 0 & 0 & 1 & 0 \\
\hline 1 & 6 & 0 & 1 & 0 & 0 & 0 & 0 & 0 & 0 & 1 & 1 \\
\hline 1 & 6 & 0 & 1 & 0 & 0 & 0 & 0 & 0 & 0 & 1 & 2 \\
\hline 1 & 6 & 0 & 1 & 0 & 0 & "“ & "“ & " & "“ & "، & "، \\
\hline 1 & 6 & 0 & 1 & 0 & 0 & 0 & 0 & 0 & 0 & 5 & 9 \\
\hline 1 & 6 & 0 & 1 & 0 & 0 & 0 & 0 & 0 & 1 & 0 & 0 \\
\hline 1 & 6 & 0 & 1 & 0 & 0 & 0 & 0 & 0 & 1 & 0 & 1 \\
\hline 1 & 6 & 0 & 1 & 0 & 0 & "، & "“ & "“ & "، & “" & "، \\
\hline 1 & 6 & 0 & 1 & 0 & 0 & 0 & 0 & 5 & 9 & 5 & 9 \\
\hline 1 & 6 & 0 & 1 & 0 & 0 & 0 & 1 & 0 & 0 & 0 & 0 \\
\hline 1 & 6 & 0 & 1 & 0 & 0 & 0 & 1 & 0 & 0 & 0 & 1 \\
\hline 1 & 6 & 0 & 1 & 0 & 0 & 0 & 1 & 0 & 0 & 0 & 2 \\
\hline 1 & 6 & 0 & 1 & 0 & 0 & “" & "، & " & " & " & "، \\
\hline 1 & 6 & 0 & 1 & 0 & 0 & 2 & 3 & 5 & 9 & 5 & 8 \\
\hline 1 & 6 & 0 & 1 & 0 & 0 & 2 & 3 & 5 & 9 & 5 & 9 \\
\hline 1 & 6 & 0 & 1 & 0 & 1 & 0 & 0 & 0 & 0 & 0 & 0 \\
\hline “" & “" & " & " & “ & " & " & "، & " & " & “ & " \\
\hline 1 & 6 & 0 & 1 & 3 & 1 & 2 & 3 & 5 & 9 & 5 & 9 \\
\hline 1 & 6 & 0 & 2 & 0 & 0 & 0 & 0 & 0 & 0 & 0 & 0 \\
\hline “" & " & “" & "، & " & "، & " & " & " & " & " & "، \\
\hline 1 & 6 & 0 & 2 & 2 & 8 & 2 & 3 & 5 & 9 & 5 & 9 \\
\hline 1 & 6 & 0 & 3 & 0 & 0 & 0 & 0 & 0 & 0 & 0 & 0 \\
\hline “" & "، & "، & "، & "، & "، & "، & " & " & “" & " & "“ \\
\hline 1 & 6 & 0 & 3 & 3 & 1 & 2 & 3 & 5 & 9 & 5 & 9 \\
\hline 1 & 6 & 0 & 4 & 0 & 0 & 0 & 0 & 0 & 0 & 0 & 0 \\
\hline " & " & " & "“ & " & " & " & " & " & " & " & " \\
\hline 1 & 6 & 0 & 4 & 3 & 0 & 2 & 3 & 5 & 9 & 5 & 9 \\
\hline 1 & 6 & 0 & 5 & 0 & 0 & 0 & 0 & 0 & 0 & 0 & 0 \\
\hline " & "، & “" & “" & " & "، & "“ & "“ & "“ & "، & "، & "، \\
\hline 1 & 6 & 1 & 2 & 3 & 1 & 2 & 3 & 5 & 9 & 5 & 9 \\
\hline 1 & 7 & 0 & 1 & 0 & 0 & 0 & 0 & 0 & 0 & 0 & 0 \\
\hline "6 & $" 6$ & "6 & $"$ & 6 & "“ & " & $" 6$ & "“ & " & " & " \\
\hline
\end{tabular}

The Table 2 shows the assembly language program of 8051 microcontroller to display 24 hours time and 2 digits years. The program one executed, it gives exact values up to a period of 99 years. Precautions were taken in the assembly language program to change the values in a leaf year for every 4 years. The delay program gives exactly 1 second delay, so that the clock works accurately without any deviation. Two address locations were written with NOP instructions to modify the value of delay time by introducing an extra register. The suitable address locations of 8051 microcontroller memory used in our laboratory starts from $8000 \mathrm{H}$ onwards.

We successfully verified the program of displaying of a time on seven segment displays through 8051 assembly language program. Due to time restrictions we could n't verified the program of displaying of the date. We expected that the program could be worked out. 
Displaying of Digital Clock through digital circuits and through Assembly Language Programs of ..

Table 2: Assembly language program for 8051 microcontroller to display Days at Port A, Months at port B and years at port $\mathrm{C}$ of $8255 \mathrm{PPI}$. ORG 8000 ; Initial address of the program

\begin{tabular}{|c|c|c|c|}
\hline Address & Label field & Mnemonic field & Comments field \\
\hline \multicolumn{3}{|c|}{ Main Program } & Origin of the program from $8000 \mathrm{H}$ \\
\hline 8000 & & MOV DPTR,\#2043H & ; Load DPTR with Control port Address of $2^{\text {nd }} 8255$ \\
\hline 8003 & & MOV A,\#80 & ; $(\mathrm{A})=80 \mathrm{H}=$ control word for all ports as output ports \\
\hline 8005 & & MOV R7,\#16H & $;(\mathrm{R} 7)=16 \mathrm{H}=$ to display $16^{\text {th }}$ year on years displays \\
\hline 8007 & & MOV DPTR,\#2042H & ; Load DPTR with port C Address of $2^{\text {nd }} 8255$ \\
\hline $800 \mathrm{~A}$ & & MOV A,R7 & $;(\mathrm{A})=16 \mathrm{H}$ \\
\hline $800 \mathrm{~B}$ & & MOVX @DPTR,A & ; Display $16 \mathrm{H}$ at port $\mathrm{C}$ of 8255 \\
\hline $800 \mathrm{C}$ & & MOV R6,\#00 & $;(\mathrm{R} 6)=00$ \\
\hline $800 \mathrm{E}$ & & ACALL Month & ; Call month routine to display January \\
\hline 8010 & & MOV R5,\#0 & ; (R5) $=0=$ first Day on Days displays \\
\hline 8012 & & ACALL Day & ; Call the routine Day to display day at port A \\
\hline 8014 & & CJNE R5,\#1FH,Day1 & $\begin{array}{l}\text {; Compare R5 with } 1 \mathrm{FH} \text { (i.e. } 31_{10} \text { ), if } \mathrm{R} 5 \neq 1 \mathrm{FH} \text { then } \\
\text { jump to Day1. No need of involving Accumulator in } \\
\text { compare }\end{array}$ \\
\hline 8017 & & ACALL Month & ; Call month routine to display February \\
\hline 8019 & & MOV R5,\#0 & $;(\mathrm{R} 5)=0=$ to display beginning of the Day \\
\hline $801 \mathrm{~B}$ & & ACALL Day & ; Call the routine Day to display day at port A \\
\hline $801 \mathrm{D}$ & & CJNE R5,\#1CH,Day1 & $\begin{array}{l}\text {; Compare R5 with } 1 \mathrm{CH} \text { (i.e. } 28_{10} \text { ), if } \mathrm{R} 5 \neq 1 \mathrm{CH} \text { then } \\
\text { jump to Day } 1 . \text { In February month there are } 28 \text { days }\end{array}$ \\
\hline 8020 & & ACALL Month & ; Call month routine to display March \\
\hline 8022 & & MOV R5,\#0 & ; (R5) $=0=$ first Day on Days displays \\
\hline 8024 & & ACALL Day & ; Call the routine Day to display day at port A \\
\hline 8026 & & CJNE R5,\#1FH,Day1 & $\begin{array}{l}\text {; Compare R5 with } 1 \mathrm{FH} \text { (i.e. } 31_{10} \text { ), if } \mathrm{R} 5 \neq 1 \mathrm{FH} \text { then } \\
\text { jump to Day1. No need of involving Accumulator in } \\
\text { compare }\end{array}$ \\
\hline 8029 & & ACALL Month & ; Call month routine to display April \\
\hline $802 \mathrm{~B}$ & BACK: & MOV R5,\#0 & ; (R5) $=0=$ first Day on Days displays \\
\hline $802 \mathrm{D}$ & & ACALL Day & ; Call the routine Day to display day at port A \\
\hline $802 \mathrm{~F}$ & & CJNE R5,\#1EH,Day1 & ; Compare R5 with $30_{10}$, if R5 $\neq 1 \mathrm{EH}$ then jump to Day1. \\
\hline 8032 & & ACALL Month & ; Call month routine to display May / July \\
\hline 8034 & & MOV R5,\#0 & $;(\mathrm{R} 5)=0=$ to display beginning of the Day \\
\hline 8036 & & ACALL Day & ; Call the routine Day to display day at port A \\
\hline 8038 & & CJNE R5,\#1FH,Day1 & $\begin{array}{l}\text {; Compare } \mathrm{R} 5 \text { with } 31_{10} \text {, if } \mathrm{R} 5 \neq 1 \mathrm{FH} \text { then jump to } \\
\text { Day1. }\end{array}$ \\
\hline $803 \mathrm{~B}$ & & ACALL Month & ; Call month routine to display June / August \\
\hline 803D & & CJNE R6,\#08,BACK & $\begin{array}{l}\text {; Compare R6 with } 07 \text { (July), if R6 } 607 \text { then jump } \\
\text { toBACK. }\end{array}$ \\
\hline 8040 & & MOV R5,\#0 & $;(\mathrm{R} 5)=0=$ to display beginning of the Day \\
\hline 8042 & & ACALL Day & ; Call the routine Day to display day at port A \\
\hline 8044 & & CJNE R5,\#1FH,Day1 & $\begin{array}{l}\text {; Compare } \mathrm{R} 5 \text { with } 31_{10} \text {, if } \mathrm{R} 5 \neq 1 \mathrm{FH} \text { then jump to } \\
\text { Day1. }\end{array}$ \\
\hline 8047 & & ACALL Month & ; Call month routine to display September \\
\hline 8049 & BACK1: & MOV R5,\#0 & ; (R5) $=0=$ first Day on Days displays \\
\hline $804 \mathrm{~B}$ & & ACALL Day & ; Call the routine Day to display day at port A \\
\hline 804D & & CJNE R5,\#1EH,Day1 & $\begin{array}{l}\text {; Compare R5 with } 1 \mathrm{EH} \text { (i.e. } 30_{10} \text { ), if R } 5 \neq 1 \mathrm{EH} \text { then } \\
\text { jump to Day1. No need of involving Accumulator in } \\
\text { compare }\end{array}$ \\
\hline 8050 & & ACALL Month & ; Call month routine to display October / December \\
\hline 8052 & & MOV R5,\#0 & $;(\mathrm{R} 5)=0=$ to display beginning of the Day \\
\hline 8054 & & ACALL Day & ; Call the routine Day to display day at port A \\
\hline 8056 & & CJNE R5,\#1FH,Day1 & $\begin{array}{l}\text {; Compare } \mathrm{R} 5 \text { with } 31_{10} \text {, if } \mathrm{R} 5 \neq 1 \mathrm{FH} \text { then jump to } \\
\text { Day1. }\end{array}$ \\
\hline 8059 & & ACALL Month & ; Call month routine to display November \\
\hline $805 \mathrm{~B}$ & & CJNE R6,\#12,BACK1 & $\begin{array}{l}\text {; Compare R6 with } 12 \mathrm{H} \text {, if } \mathrm{R} 6 \neq 12 \mathrm{H} \text { then jump to } \\
\text { BACK1. }\end{array}$ \\
\hline $805 \mathrm{E}$ & & INC R7 & ; Increment the year \\
\hline $805 \mathrm{~F}$ & & SJMP START & ; Repeat the process again \\
\hline
\end{tabular}


Displaying of Digital Clock through digital circuits and through Assembly Language Programs of ..

\begin{tabular}{|c|c|c|c|}
\hline \multicolumn{4}{|c|}{ Subroutine to display month at port B } \\
\hline 9000 & Month: & INC R6 & ; Increment R6 to get next month \\
\hline 9001 & & MOV DPTR,\#2041H & ; Load DPTR with port B Address of $2^{\text {nd }} 8255$ \\
\hline 9004 & & MOV A,R6 & ;(A) = R6 \\
\hline 9005 & & DA A & ; $(\mathrm{A})=\mathrm{BCD}$ coded Decimal value \\
\hline 9006 & & MOVX @DPTR,A & ; Display next month at port B of 8255 \\
\hline 9007 & & RET & ; Return to main program \\
\hline \multicolumn{4}{|c|}{ Subroutine to display a day at port $\mathrm{A}$} \\
\hline 9008 & Day: & MOV DPTR,\#2040H & ; Load DPTR with port A Address of $2^{\text {nd }} 8255$ \\
\hline $900 \mathrm{~B}$ & Day1: & MOV A,R5 & $;(\mathrm{A})=$ day \\
\hline $900 \mathrm{C}$ & & DA A & $;(\mathrm{A})=\mathrm{BCD}$ coded Decimal value \\
\hline $900 \mathrm{D}$ & & MOVX @DPTR,A & ; Display Day on port A of 8255 \\
\hline $900 \mathrm{E}$ & & LCALL 1day & ; Call delay for 1 day $=24$ hours. \\
\hline 9012 & & INC R5 & ; Increment R5 to get next day \\
\hline 6013 & & RET & ; Return to main program \\
\hline
\end{tabular}

Table 3: The Delay Routine

\begin{tabular}{|l|l|l|l|}
\hline Address & Label field & Mnemonic field & Comments field \\
\hline FF00H & DELAY: & NOP & ; No operation \\
\hline FF01H & & NOP & ; No operation \\
\hline FF02H & & MOV R1,\#0FF & ; Load R1 register with FFH \\
\hline FF04H & LOOP2: & MOV R2,\#0FF & ; Load R2 register with FFH \\
\hline FF06H & LOOP1: & DJNZ R2,LOOP1 & $\begin{array}{l}\text {; Decrement R2 by 1 and if it is not equal to 0 } \\
\text { jump to LOOP1 (inner loop) }\end{array}$ \\
\hline FF08H & & DJNZ R1,LOOP2 & $\begin{array}{l}\text {; Decrement R1 by 1 and if it is not equal to 0 } \\
\text { jump to LOOP2 (middle loop) }\end{array}$ \\
\hline FF0AH & & NOP & ; No operation \\
\hline FF0BH & & NOP & ; No operation \\
\hline FF0CH & & RET & ; Return to the main program \\
\hline
\end{tabular}

Table 4: Assembly language program for 8051 microcontroller to display Seconds at Port A, Minutes at port B and Hours at port $\mathrm{C}$ of $8255 \mathrm{PPI}$.

\begin{tabular}{|c|c|c|c|}
\hline Address & $\begin{array}{l}\text { Label } \\
\text { field }\end{array}$ & Mnemonic field & Comments field \\
\hline 9100 & 1day: & MOV DPTR,\#2023H & ; Load DPTR with Control port Address of $1^{\text {st }} 8255$ \\
\hline 9103 & & MOV A,\#80 & $\begin{array}{l};(\mathrm{A})=80 \mathrm{H}=\text { control word for all ports as output } \\
\text { ports }\end{array}$ \\
\hline 9105 & & MOV DPTR,\#2022H & ; Load DPTR with port C Address of $1^{\text {st }} 8255$ \\
\hline 9108 & & MOV R0,\#0 & $;(\mathrm{R} 0)=00$, to display 00 hours \\
\hline $910 \mathrm{~A}$ & & MOV A,R0 & $;(\mathrm{A})=(\mathrm{R} 0)$ \\
\hline $910 \mathrm{~B}$ & & MOVX@DPTR,A & ; Display 00 hours at port $\mathrm{C}$ of 8255 \\
\hline $910 \mathrm{C}$ & BACK3: & MOV R4,\#0 & $;(\mathrm{R} 4)=00$, to display 00 minute \\
\hline $910 \mathrm{E}$ & & MOV A,R4 & $;(\mathrm{A})=(\mathrm{R} 4)$ \\
\hline $910 \mathrm{~F}$ & & MOV DPTR,\#2021H & ; Load DPTR with port B Address of $1^{\text {st }} 8255$ \\
\hline 9112 & & MOVX @DPTR,A & ; Display minutes at port B of $1^{\text {st }} 8255$ \\
\hline 9113 & BACK2: & MOV R3,\#0 & ; (R3) $=00$, to display 00 Seconds \\
\hline 9115 & & MOV A,R3 & $;(\mathrm{A})=(\mathrm{R} 3)$ \\
\hline 9116 & & MOV DPTR,\#2020H & ; Load DPTR with port A Address of $1^{\text {st }} 8255$ \\
\hline 9119 & BACK1: & MOVX @DPTR,A & ; Display Seconds at port $\mathrm{A}$ of $1^{\text {st }} 8255$ \\
\hline $911 \mathrm{~A}$ & & LCALL DELAY & ; Call 1 second DELAY routine \\
\hline 911D & & ADD A,\#01 & $;(\mathrm{A})=(\mathrm{A})+1$, to get next second \\
\hline $911 \mathrm{~F}$ & & DA A & ; Decimal adjusting A to get seconds in $\mathrm{BCD}$ format \\
\hline 9120 & & CJNE A,\#60H,BACK1 & ; If $(\mathrm{A}) \neq 60 \mathrm{H}$, then jum to $\mathrm{BACK} 1$ \\
\hline 9123 & & INC R4 & $;(\mathrm{R} 4)=(\mathrm{R} 4)+1$, to get next minute \\
\hline 9124 & & MOV DPTR,\#2021H & ; Load DPTR with port B Address of $1^{\text {st }} 8255$ \\
\hline 9127 & & MOV A,R4 & $;(\mathrm{A})=(\mathrm{R} 4)$ \\
\hline 9128 & & DA A & ; Decimal adjusting A to get minutes in $\mathrm{BCD}$ format \\
\hline
\end{tabular}


Displaying of Digital Clock through digital circuits and through Assembly Language Programs of ..

\begin{tabular}{|l|l|l|}
\hline 9129 & MOVX @DPTR,A & ; Display minutes at port B of $1^{\text {st }} 8255$ \\
\hline 912A & CJNE A,\#60H,BACK2 & $;$ If $(\mathrm{A}) \neq 60 \mathrm{H}$, then jump to BACK1 \\
\hline 912D & INC R0 & $;(\mathrm{R} 0)=(\mathrm{R} 0)+01$, to get next hour \\
\hline 912E & MOV A,R0 & $;(\mathrm{A})=(\mathrm{R} 0)$ \\
\hline 912F & DA A & ; Decimal adjusting A to get hours in BCD format \\
\hline 9130 & CJNE A,\#24H,BACK2 & ; If $(\mathrm{A}) \neq 24 \mathrm{H}$, then jump to BACK3 \\
\hline 9133 & RET & ; Return to main program \\
\hline
\end{tabular}

\section{CONCLUSIONS}

1. The modulo-n counters were used to generate a digital clock

2. Change the clock position to set or reset any of the digits in the digital clock.

3. The lower digits reaches its maximum value, it supplies a clock pulse to its higher digit.

4. When higher digits are resetting, they clears all its lower positions.

5. Two separate 8255 PPIs required to display time and date separately

6. The delay subroutine must give exactly 1 second delay to display time and date accurately.

7. It is cheapest to design the digital clock with digital circuits than with the microprocessors.

\section{ACKNOWLEDGEMENT}

The first \& corresponding author would like to express thanks to Dr. S. Jaikishan garu, the Chairman, Secretary \& Correspondent of Bhavan's New Science College for encouraging him to carry out the research work and publish papers. He also thanks the management for providing the facilities in Department of Physics to carry out the above project. He also likes to wishes his thanks to his colleagues Dr. P. Indira, Dr. S. Laxmi Srinivasa Rao (The In charge Principal of BNSC (Day)), Sri. D. Sambasiva Rao, Dr. B.V. Prasad, Dr. RVGK Mohan, Dr. S. Jagan Mohan, Mr. B. Anjaiah, Ms. Shahenn Sk, Mr. N. Venkateswar Reddy and Ms. Asiya for their encouragement and support. He would also like to express his thanks to Mr. Balraj, Mr. Suresh, Mr. Sriram, the Non teaching staff of Dept. of Physics of BNSC for their support.
He also wishes his thanks to his family members and friends for their support. He would like to convey his best wishes to his small kid Master Krishna Chaithanya, who makes the author in a refreshing mind by his smile and kidding actions. Finally he would like to express his thanks to his M.Sc. Applied Electronics students for their support.

\section{REFERENCES}

[1] R.P. Jain and M.M.S. Anand; Digital Electronics Practice using Integrated Circuits, Tata McGraw-Hill Publishing Company Limited, New Delhi.

[2] Dr. D. Chinni Krishna, Volume 3, Number 2, Gaussian Journal of Science \& Applications, July-December 2015. ISSN: 2348-0440

[3] Muhammad Ali Mazidi, Jainice Gillispie Mazidi and Rolin D. McKinlay; The 8051 Microcontrollers and Embedded Systems using Assembly and C, Second Edition, Eastern Economy Edition-2006, Prentice Hall of India Private Limited, New Delhi110001. 